\title{
Genomic upregulation of cardiac Cav1.2a and NCX1 by estrogen in women
}

\author{
Rita Papp ${ }^{1,7}$, Glenna C. L. Bett ${ }^{2,3,4}$, Agnieszka Lis ${ }^{2,3}$, Randall L. Rasmusson ${ }^{2,3}$, István Baczkó ${ }^{5}$, András Varró 5,6 \\ and Guy Salama ${ }^{1,8^{*}}$
}

\begin{abstract}
Background: Women have a higher risk of lethal arrhythmias than men in long QT syndrome type 2 (LQTS2), but the mechanisms remain uncertain due to the limited availability of healthy control human tissue. We have previously reported that in female rabbits, estrogen increases arrhythmia risk in drug-induced LQTS2 by upregulating L-type $\mathrm{Ca}^{2+}$ $\left(I_{C, L}\right)$ and sodium-calcium exchange $\left(I_{N C X}\right)$ currents at the base of the epicardium by a genomic mechanism. This study investigates if the effects of estrogen on rabbit $I_{C a, L}$ and $I_{N C X}$ apply to human hearts.

Methods: Postmortem human left ventricular tissue samples were probed with selective antibodies for regional heterogeneities of ion channel protein expression and compared to rabbit myocardium. Functionally, $I_{C a, L}$ and $I_{N C X}$ were measured from female and male cardiomyocytes derived from human induced pluripotent stem cells (iPS-CMs) with the voltage-clamp technique from control and estrogen-treated iPS-CMs.

Results: In women $(n=12)$, Cav1.2a (primary subunit of the L-type calcium channel protein 1 ) and NCX1 (sodium-calcium exchange protein) levels were higher at the base than apex of the epicardium (40 \pm 14 and $81 \pm 30 \%$, respectively, $P<0.05)$, but not in men $(n=6)$ or postmenopausal women $(n=6)$. Similarly, in cardiomyocytes derived from female human iPS-CMs, estrogen $\left(1 \mathrm{nM}, 1-2\right.$ days) increased $I_{C a, L}(31 \%, P<0.05)$ and $I_{\text {NCX }}(7.5$-fold, $-90 \mathrm{mV}, P<0.01)$ and their mRNA levels $(P<0.05)$. Moreover, in male human iPS-CMs, estrogen failed to alter $I_{C a, L}$ and $I_{N C X}$.

Conclusions: The results show that estrogen upregulates cardiac $I_{C a, L}$ and $I_{N C X}$ in women through genomic mechanisms that account for sex differences in $\mathrm{Ca}^{2+}$ handling and spatial heterogeneities of repolarization due to base-apex heterogeneities of Cav1.2a and NCX1. By analogy with rabbit studies, these effects account for human sex-difference in arrhythmia risk.
\end{abstract}

Keywords: Sex differences in the human heart, Sex differences in arrhythmia phenotype, 17- $\beta$-estradiol, L-type $\mathrm{Ca}^{2+}$ channel, Sodium-calcium exchanger, Regional heterogeneities in the heart

\section{Background}

Sex-dependent arrhythmia risks are particularly pronounced when there is repolarization delay such as in bradycardia and congenital or drug-induced long QT syndrome type 2 (LQTS2). Prolongation of the cardiac action potential (AP) is caused by an imbalance between the depolarizing and repolarizing ionic currents resulting

\footnotetext{
* Correspondence: gsalama@pitt.edu

'Department of Bioengineering and the Department of Medicine, Heart and Vascular Institute, University of Pittsburgh, Pittsburgh, PA 15261, USA

${ }^{8}$ Department of Bioengineering and the Department of Medicine, Heart and Vascular Institute, University of Pittsburgh, 3550 Terrace Street, S628 Scaife Hall, Pittsburgh, PA 15261, USA

Full list of author information is available at the end of the article
}

in an accompanying prolongation of the QT interval on the EKG. Congenital long QT type 2 (LQT2) is caused by mutations of the Kv11.1 $\mathrm{K}^{+}$channel protein (hERG). This results in a loss of function of the rapid component of the delayed rectifying $\mathrm{K}^{+}$current, $\mathrm{I}_{\mathrm{Kr}}$ thus prolonging AP duration (APD) and QT interval [1]. Although the incidence of all forms of congenital LQT is rare $(<1 /$ 5000), drug-induced LQTS remains a particularly serious public health problem in terms of safety pharmacology [2-4] because a wide range of cardiac and non-cardiac drugs suppress $\mathrm{I}_{\mathrm{Kr}}$ prolong APDs, and promote early afterdepolarizations (EADs) that lead to potentially lethal torsade de pointes (TdP) $[1,5-8]$. Women are at much 
greater risk than men of experiencing drug-induced LQTS and developing TdP [9-11].

There is general agreement that torsade de pointes is initiated by EADs. "Early" EADs that occur early during the plateau phase of the AP may be caused by the spontaneous reactivation of L-type $\mathrm{Ca}^{2+}$ channels [12], whereas "late" EADs that arise in a later phase of the AP plateau are caused by an imbalance between the $\mathrm{Ca}^{2+}$ influx and efflux resulting in sarcoplasmic reticulum (SR) $\mathrm{Ca}^{2+}$ overload, spontaneous $\mathrm{SR} \mathrm{Ca}^{2+}$ release, and activation of the forward mode of the $\mathrm{Na}-\mathrm{Ca}$ exchanger (NCX) current which can further prolong the AP and trigger EADs by the reactivation of the L-type $\mathrm{Ca}^{2+}$ current $\left(\mathrm{I}_{\mathrm{Ca}, \mathrm{L}}\right)[13,14]$.

A salient feature of LQT2 is the marked sex difference in arrhythmia risk: women are twice as likely as men to experience $\mathrm{TdP}$ as a result of inherited LQT2 or druginduced LQT $[11,15,16]$. These differences disappear in postmenopausal women over the age of $50[9,15,16]$. It should be noted that postmenopausal women with congenital LQT2 have a higher recurrence of syncope, and these repeated syncope events were not attributed to $\mathrm{TdP}$ [17]. Sex differences in arrhythmia risk have been attributed to a reduced "repolarization reserve" in adult women, consistent with their longer rate-corrected QT (QTc) intervals and hence greater susceptibility to $\mathrm{I}_{\mathrm{Kr}}$ blockade than men $[10,18]$. However, the QT interval is not an accurate predictor of arrhythmia risk, with asymptomatic individuals having long QT and conversely individuals with QT intervals in the normal range exhibiting severe arrhythmias [19]. A major challenge to unraveling the molecular mechanisms underlying LQT-related arrhythmias is the lack of available human myocardial tissues. As a result, animal models have been extensively used to study human sex differences, but data are difficult to interpret due to differences in ion channels expressed in the heart, different effects of sex steroids, and different propensities to arrhythmia. In a recent analysis of the data, we proposed that the rabbit may be the best surrogate to study sex differences in humans [20].

The higher risk of LQT2-related arrhythmias in women is likewise observed in female New Zealand White rabbits compared to their male counterparts [21], and the risk is reversed in both pre-pubertal rabbits [22] and man [23]. In female rabbits, ovariectomy was protective of druginduced LQT2-related arrhythmias whereas $17-\beta$-estradiol replacement reversed the protective effects of ovariectomy and promoted EADs and arrhythmias [24-26]. These studies suggest that $17-\beta$-estradiol promotes TdP in female hearts.

Dual optical mapping of action potentials (APs) and intracellular free $\mathrm{Ca}^{2+}\left(\mathrm{Ca}_{\mathrm{i}}\right)$ transients in a Langendorff rabbit model of drug-induced LQT2 revealed that adult female hearts were more prone to EADs and TdP and that the origins of EADs and $\mathrm{Ca}_{\mathrm{i}}$ oscillations preceded the occurrence EADs [27, 28] [21]. We also showed that in freshly isolated ventricular myocytes, peak $\mathrm{I}_{\mathrm{Ca}, \mathrm{L}}$ density and Cav1.2 $\alpha$ (primary subunit of the L-type $\mathrm{Ca}^{2+}$ channel protein) channel protein were $25-30 \%$ greater at the base than the apex of adult female compared to male hearts [21]. Western blot analysis and voltage-clamp studies showed that the higher level of Cav1.2 $\alpha$ at the base of the adult female heart was associated with a regional elevation of NCX and $\mathrm{I}_{\mathrm{NCX}}[14,21,29]$. These findings are congruent with data from humans since cardiac contractility is greater in women than men [30] and myocytes isolated from women post-transplantation have a tendency to have greater $\mathrm{I}_{\mathrm{Ca}, \mathrm{L}}$ than men [31].

Moreover, incubation of myocytes with $17-\beta$-estradiol (E2; $1 \mathrm{nM}$ ) revealed a regional genomic upregulation of NCX and Cav1.2 $\alpha$, mRNA, protein levels, and their respective current densities, $\mathrm{I}_{\mathrm{NCX}}$ and $\mathrm{I}_{\mathrm{Ca}, \mathrm{L}}$. These effects are mediated by estrogen receptors, enhanced transcription and protein biosynthesis of NCX, and Cav1.2 $\alpha$ channel protein $[14,32]$. We extended these studies by showing that E2 upregulates $\mathrm{I}_{\mathrm{Ca}, \mathrm{L}}$ in cultured myocytes isolated from the base of female hearts by a genomic mechanism mediated via the $\alpha$ isoform of estrogen receptors (ER $\alpha)$ but not via the $\beta$ isoform (ER $\beta$ ) [32].

Our findings in rabbit hearts [21] were consistent with a report of endocardium-to-epicardium dispersion of $\mathrm{I}_{\mathrm{Ca}, \mathrm{L}}$ in female but not in male rabbit hearts and with $\mathrm{I}_{\mathrm{Ca}, \mathrm{L}}$ density being higher on the epicardium than the endocardium and no male-female differences on the endocardium [33].

These findings raise the question of whether in men similar mechanisms explain sex differences in arrhythmia risk in LQTS. Here, we analyzed heterogeneities in the expression of ion channels and $\mathrm{Ca}^{2}$ ${ }^{+}$-transport proteins from the base and apex of the left ventricular epicardium of healthy human donor hearts. In addition, the possible role of estrogen-mediated genomic regulation of protein expression was evaluated (a) indirectly by introducing a third study group of postmenopausal women who were older than 50 years and thus expected to have significantly lower levels of estrogen than younger adult women and (b) treating female and male human cardiac myocytes derived from induced pluripotent stem cells with E2 followed by voltage-clamp measurements of $\mathrm{I}_{\mathrm{Ca}, \mathrm{L}}$ and $\mathrm{I}_{\mathrm{NCX}}$ and their corresponding mRNA levels.

\section{Methods}

\section{Human and rabbit tissue samples}

Hearts were obtained from organ donors whose nondiseased hearts were explanted to obtain pulmonary and aortic valves for transplant surgery. Before cardiac explantation, organ donors did not receive medication apart from dobutamine, furosemide, and plasma expanders. 
The investigations conformed to the principles of the Declaration of Helsinki. The experimental protocols were approved by the University of Szeged and National Scientific and Research Ethical Review Boards (No. 51$57 / 1997 \mathrm{OEj}$ ) and by the Scientific and Research Ethical Committee of the Medical Scientific Board at the Hungarian Ministry of Health (ETT-TUKEB) under ethical approval No. 4991-0/2010-1018EKU (339/PI/010).

After explantation, each heart was perfused with cardioplegic solution and kept cold $\left(4-6{ }^{\circ} \mathrm{C}\right)$ for $2-4 \mathrm{~h}$ prior to dissection. Tissue samples were excised from the subepicardial and subendocardial layers of the left ventricular base and the subepicardium of the left ventricular apex. Samples were flash-frozen in liquid nitrogen and stored at $-80{ }^{\circ} \mathrm{C}$ until use. Three groups of myocardial samples were analyzed: adult men $(n=6)$, adult women (between the ages of 17 and 49 years, $n=11)$, and postmenopausal women ( $>50$ years, $n=6$ ); the minimum, maximum, and mean ages for each group are shown by Table 1 .

For rabbit cardiac samples, 3-month-old male $(n=2)$ and female $(n=3)$ New Zealand White rabbits were heparinized (200 U/kg i.v.) and euthanized with an intravenous injection of sodium pentobarbital $(50 \mathrm{mg} / \mathrm{kg})$. The hearts were excised and perfused through the aorta with ice-cold Tyrode's solution for $5 \mathrm{~min}$, then cardiac tissue samples were harvested from the base and apex of the left ventricular epicardium, as previously described [21]. In previous reports, the base-apex heterogeneities of Cav1.2 $\alpha 1$ and NCX1 (sodium-calcium exchange protein) on the epicardium were shown to occur in female but not male adult rabbit hearts [21]. We also reported spatial heterogeneities along the right ventricle and included the spatial heterogeneities of SERCA2a, RyR2, Nav1.5, and hERG [29]. Here, we probed all the above channels (see Fig. 2) from the left ventricles of a new set of male and female adult rabbits.

Protocols were approved by the University of Pittsburgh Institutional Animal Care and Use Committee and were in accordance with the current Guide for the Care and Use of Laboratory Animals published by the National Institutes of Health. These studies also comply with the procurement of the rabbits, and the animal husbandry and the experiments conform to the "European Convention for the Protection of Vertebrate Animals used for Experimental and other Scientific Purposes" (Council of Europe No 123, Strasbourg 1985). Western blot results were pooled together with earlier

Table 1 Summary of the number of individuals ( $n$ ) and ages of the human used in the study

\begin{tabular}{llll}
\hline Group & $\begin{array}{l}\text { Men } \\
(n=6)\end{array}$ & $\begin{array}{l}\text { Adult women } \\
(n=11)\end{array}$ & $\begin{array}{l}\text { Postmenopausal } \\
\text { women }(n=6)\end{array}$ \\
\hline Mean age (years) & 45 & 34 & 56 \\
Min-Max (years) & $32-58$ & $17-49$ & $51-68$ \\
\hline
\end{tabular}

Cav1.2 $\alpha 1[21,32]$ and NCX1 data [14], while, for the other proteins, earlier samples from 3 female and 3 male hearts were run in addition to our freshly isolated samples, reaching a total $\mathrm{n}$ number of $n=6$ for female and $n=5$ for male rabbits.

\section{Western blots}

Cardiac tissue samples were pulverized in liquid nitrogen; then approximately $100 \mathrm{mg}$ of tissue powder were suspended in lysis buffer containing (in $\mathrm{mM}$ ) $150 \mathrm{NaCl}, 1$ EDTA, $2.5 \mathrm{MgCl}_{2}$, $20 \mathrm{HEPES}, 1 \%$ Triton X-100, and $0.1 \%$ SDS as well as protease inhibitor cocktail and PMSF (both from Sigma), then homogenized with a glass-teflon homogenizer. After 20-min centrifugation at 16,000g, the supernatants were collected, and the protein concentration was determined with the Bradford protein assay (Bio-Rad Laboratories, Hercules, CA, USA). Fifty micrograms of total protein samples were ran on $4-15 \%$ polyacrylamide gels (Bio-Rad), then transferred to PVDF membranes (Millipore). After blocking with 5\% milk, the membranes were incubated overnight with primary antibodies against Cav1.2 $\alpha 1$ (rabbit: Santa Cruz sc103588, 1:100; human: custom antibody from Zymed, 1:250), NCX1 (Thermo Scientific MA3-926, 1:500), SERCA2a (Santa Cruz sc53010, 1:1000), RyR2 (Thermo Scientific MA3-916, 1:500), Nav 1.5 (Alomone Laboratories ASC-005, 1:100), hERG (Santa Cruz sc15968, 1:100), and GAPDH (glyceraldehyde 3phosphate dehydrogenase; Abcam ab70136, 1:1000). After incubation with alkaline phosphatase conjugated secondary antibodies (Jackson ImmunoResearch), blots were developed with the Lumi-Phos reagent (Thermo Scientific), then imaged and analyzed with the Image Lab GelDoc system (Bio-Rad). Band intensities were normalized for GAPDH as a loading control.

In order to immunolabel Cav1.2 $\alpha 1$ in human samples, several antibodies were tested including SC 103588 from Santa Cruz, ACC-003 from Alomone, and Ab 81980 and Ab 84814 from Abcam; however, these antibodies did not give satisfactory results. Therefore, a custom-made antibody produced by Zymed was used, which gave a single band around $250 \mathrm{kDa}$, and this band disappeared when the antibody was pre-incubated with the immunogen peptide.

Protein expression was compared for the three groups (4 men, 6 adult females, and 4 postmenopausal females) between the base and apex of the left ventricular epicardium, the epi, and the endocardium of the left ventricular base. Left ventricular samples from the base of the three groups were run on the same gel.

\section{iPS-CM cell culture}

Commercially available human male and female iPSCderived cardiac myocytes (iPS-CMs, Axol Bioscience, UK) were prepared according to the manufacturer's 
Table 2 Nucleotide sequence of primers used

\begin{tabular}{ll}
\hline GAPDH-F & 5'-AAT TGA GCC CGC AGC CTC CC-3' \\
GAPDH-R & 5'-GAG CGA TGT GGC TCG GCT GG-3' \\
Troponin-F & 5'-CAA GCA GGT GAA GAA GGA GG-3' \\
Troponin-R & 5'-CAG TAG GCA GGA AGG CTC AG-3' \\
Cav1.2a-R & 5'-GCC TAC CTC CGC AAC GGC TG-3' \\
Cav1.2a-F & 5'-CGG CCC CT TCC CTC CGA GA-3' \\
NCX-F & 5'-ACC TGT TTG GCC AAC CTG TCT TCA-3' \\
NCX-R & 5'-TGC TGG TCA GTG GCT GCT TGT-3 \\
\hline
\end{tabular}

instructions. Briefly, cardiac myocytes $(1 \mathrm{ml}$, stored frozen in liquid $\mathrm{N}_{2}$ ) thawed in a $37{ }^{\circ} \mathrm{C}$ water bath were initially suspended in $1 \mathrm{ml}$ Axol Complete Cardiomyocyte Medium (warmed to $37{ }^{\circ} \mathrm{C}$ ). An additional $8 \mathrm{ml}$ of medium was added and mixed by gentle inversion. Cardiac myocytes were seeded (25,000 cells/well) in $1.5 \mathrm{ml}$ medium in 12 well culture plates that contained glass coverslips (15-mm diameter, Warner Instruments, CT)

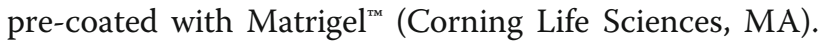

Cells were incubated for $24 \mathrm{~h}$ at $37{ }^{\circ} \mathrm{C}, 7 \% \mathrm{CO}_{2}$. Nonadherent cells were removed by rinsing with media. After 7 days in culture, 17- $\beta$-estradiol (Sigma) was added to the media at a final concentration of $1 \mathrm{nM}$. The iPSCMs were kept in 17- $\beta$-estradiol for 24-48 h before measuring $\mathrm{I}_{\mathrm{Ca}, \mathrm{L}}$ or $\mathrm{I}_{\mathrm{NCX}}$ by voltage-clamp technique. Control cells were treated with media containing DMSO $(<0.1 \%)$. Cultured iPS-CMs had a tendency to mature and exhibit spontaneous contractions by the 7th day of incubation. The male and female iPS-CMs used in this study had common features found in all iPS-CMs: spontaneous automaticity and contractions and stable ionic currents for weeks, as previously reported [34].

\section{Electrophysiology}

Electrophysiological measurements were performed in the whole-cell voltage-clamp configuration. Glass recording electrodes with resistances of 1-1.5 $\mathrm{M} \Omega$ were pulled from borosilicate glass (T1W150-4. World Precision Instruments, FL) using a Sutter micropipette puller. For recording $\mathrm{I}_{\mathrm{Ca}, \mathrm{L}}$, pipettes were filled with (in $\mathrm{mM}$ ):

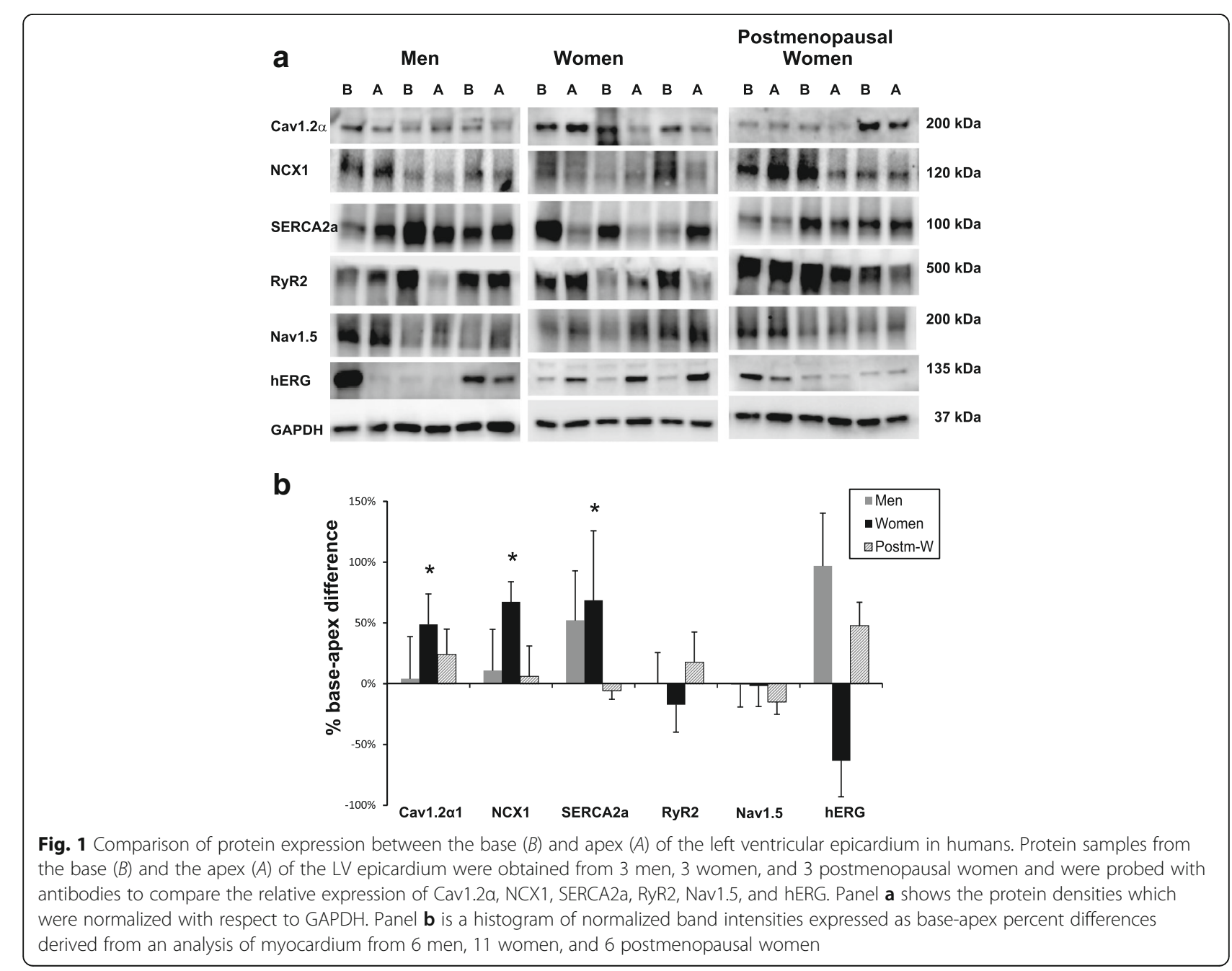


$115 \mathrm{CsCl}, 20$ TEA-Cl, $1 \mathrm{MgSO}_{4}$, 5 EGTA, 5 MgATP, 5 Tris-creatine $\mathrm{PO}_{4}, \quad 0.3$ Tris-GTP, and 10 HEPES (pH 7.2). The external solution contained (in $\mathrm{mM}$ ): 144 NMDG-Cl, $12 \mathrm{CsCl}, 2 \mathrm{CaCl}_{2}, 1 \mathrm{MgCl}_{2}, 10$ HEPES, and 10 glucose $(\mathrm{pH} 7.35)$. Cells were clamped at $-80 \mathrm{mV}$ with currents recorded over a 500-ms voltage step from the holding potential to potentials between -110 and $70 \mathrm{mV}$ in increments of $10 \mathrm{mV}$. For recording $\mathrm{I}_{\mathrm{NCX}}$, pipettes were filled with (in $\mathrm{mM}$ ): 120 glutamic acid, 120 $\mathrm{CsOH}, 0.5 \mathrm{MgSO}_{4}, 20 \mathrm{NaCl}, 10$ EGTA, $3 \mathrm{CaCl}_{2}, 5$ MgATP, and 10 HEPES (pH 7.2). The external solution contained (in mM): $140 \mathrm{NaCl}, 10 \mathrm{CsCl}_{2}, 1 \mathrm{CaCl}_{2}, 1$ $\mathrm{MgCl}_{2}, 10$ HEPES, and 10 glucose (pH 7.4). Nifedipine $(10 \mu \mathrm{M})$ and ouabain $(10 \mu \mathrm{M})$ were added to the external solution to inhibit $\mathrm{I}_{\mathrm{ca}, \mathrm{L}}$ and the Na-K ATPase, respectively. Cells were clamped at $-50 \mathrm{mV}$ and then stepped to $+100 \mathrm{mV}$ for $80 \mathrm{~ms}$ followed by a descending voltage ramp from +100 to $-120 \mathrm{mV}$ over $1600 \mathrm{~ms}$. $\mathrm{I}_{\mathrm{NCX}}$ was determined by measuring the $\mathrm{Ni}^{2+}$-sensitive current in the voltage ramp. The residual currents measured in the presence of $5 \mathrm{mM} \mathrm{Ni}^{2+}$ were subtracted from the total current recorded in the absence of $\mathrm{Ni}^{2+}$. All measured currents were normalized to the cell capacitance.

\section{qRT-PCR}

On days 2, 3, and 4 after initial treatment with betaestradiol, RNA was isolated from treated and vehicle (DMSO) control wells using a RNeasy Micro Kit (Qiagen) according to the manufacturer's instruction. cDNA was prepared from the isolated RNA $(1 \mu \mathrm{g})$ using a QuantiTect Reverse Transcription kit (Qiagen). Table 2 shows the nucleotide sequence of the primers used in the study. Quantitative real-time PCR (qPCR) was performed using the iQ SYBR Green Supermix (Bio-Rad). Samples were amplified in triplicate. Amplifications were performed using the MyIQ Real-time PCR detection system (Bio-Rad). Conditions were as follows: $50{ }^{\circ} \mathrm{C}$ for 2 min, 1 cycle; $95^{\circ} \mathrm{C}$ for $3 \mathrm{~min}, 1$ cycle; $95^{\circ} \mathrm{C}$ for $15 \mathrm{~s} \rightarrow$ $60{ }^{\circ} \mathrm{C}$ for 1 min, 40 cycles; followed by a melting curve analysis: $55-95{ }^{\circ} \mathrm{C}$ in $0.5{ }^{\circ} \mathrm{C}$ increments for $2 \mathrm{~s}$ a step. Data was analyzed using IQ 5 Optical System Software (Bio-Rad), and Excel using the $\Delta \Delta \mathrm{C}_{\mathrm{t}}$ method.

\section{Statistical analysis}

Data are shown as mean \pm SEM of the percentage differences between the base and apex or between the epicardium and endocardium, respectively. Base vs apex and epicardial vs endocardial protein levels were compared with the paired $t$ test, and differences were considered significant at $P \leq 0.05$. Patch clamp data are shown as mean \pm SEM normalized to cell capacitance. Results were compared with the unpaired $t$ test and were considered significant at $P \leq 0.05$.

\section{Results}

From left ventricular epicardial tissue samples, we found that adult women $(n=11)$, but not men $(n=6)$ or postmenopausal women $(n=6)$, had a higher expression of Cav1.2 $\alpha 1$ and NCX1 (40 \pm 14 and $81 \pm 30 \%$, respectively, $P<0.05$ ) at the base compared to the apex (Fig. 1a, b). These regional differences were similar to those found in female rabbits (106 \pm 50 and $185 \pm 53 \%$, respectively) (Fig. 2). In women, SERCA2a was also more abundant at the base compared to the apex $(130 \pm 67 \%)$, and this large spatial gradient was not observed in men or postmenopausal women. In contrast, female rabbits did not have a difference in SERCA2 expression, but male rabbit hearts had significantly higher expression of SERCA2a at the base than apex (Fig. 2). On the other hand, Nav1.5 protein expression, which exhibited a base-apex difference in female rabbits, was homogeneous throughout the epicardium in all human groups. No significant differences in the expression of RyR2 occurred in any group, in any species. In rabbits, the expression of rERG was higher at the apex in both sexes. In contrast, hERG expression in humans had a similar tendency (statistically not significant) in women (Fig. 1), whereas, in men and postmenopausal women, hERG had a tendency to be more

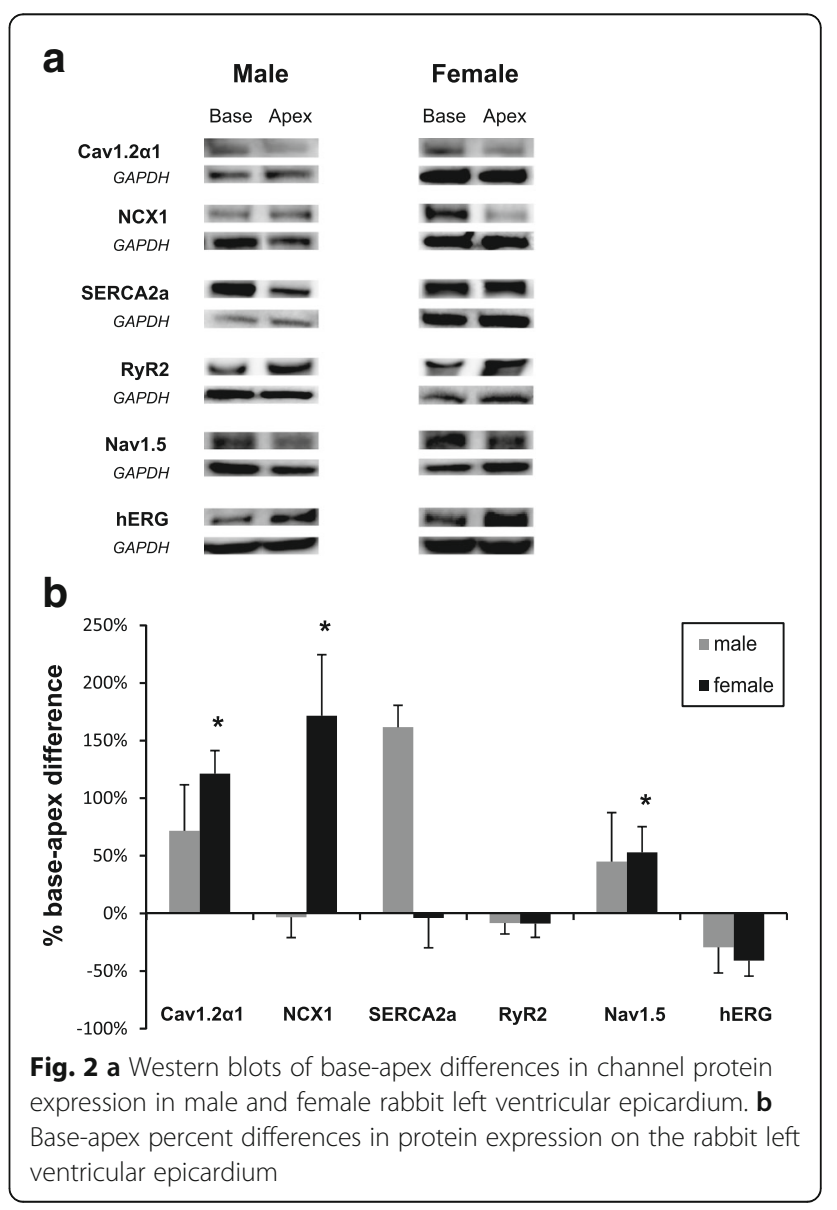


abundant at the base. Table 3 summarizes the distribution of key ion channel proteins in human myocardium and calculations regarding their base-apex differences.

Cav1.2 $\alpha$ and NCX1 showed a tendency to be more abundant on the epicardium compared to the endocardium, but these differences did not reach statistical significance in any of the groups (Fig. 3). SERCA2a was significantly higher on the epicardium compared to the endocardium, but this effect was not sex-related since it occurred in all the three human study groups (men $197 \pm 69 \%$, adult women $131 \pm 39 \%$, postmenopausal women $190 \pm 105 \%)$. Nav1.5 showed a tendency to be more abundant on the endocardium, but did not reach statistical significance except in postmenopausal women. hERG had a tendency of higher levels on the endocardium that did not reach statistical significance.

\section{Effects of E2 on human iPS-CMs}

Female cardiomyocytes derived from induced pluripotent stem cells (iPS-CM) were cultured with $1 \mathrm{nM} 17-\beta-$ estradiol (E2) or vehicle (control) for 1-3 days; then $\mathrm{I}_{\mathrm{Ca}, \mathrm{L}}$ density was recorded as a function of membrane potential $\left(V_{m}\right)$. E2-treated myocytes had a significantly higher peak current compared to vehicle-treated iPS-CMs (from $4.64 \pm 0.35(n=15)$ to $-6.09 \pm 0.55 \mathrm{pA} / \mathrm{pF} ; n=13$, at $0 \mathrm{mV}, \mathrm{P}<0.05)$ (Fig. 4a). Similarly, the $\mathrm{Ni}^{2+}$-sensitive Na$\mathrm{Ca}$ exchange current, $\mathrm{I}_{\mathrm{NCX}}$, was significantly larger in iPSCMs treated with E2 (1 nM) compared to myocytes treated with vehicle (Fig. 4b. At $-90 \mathrm{mV}, \mathrm{I}_{\mathrm{NCX}}$ current density in iPS-CMs incubated with E2 was $-2.20 \pm 0.54 \mathrm{pA} / \mathrm{pF}$ $(n=5)$ compared to $-0.29 \pm 0.13 \mathrm{pA} / \mathrm{pF}(n=5, P<0.01)$. The increases in $\mathrm{I}_{\mathrm{Ca}, \mathrm{L}}$ and $\mathrm{I}_{\mathrm{NCX}}$ densities were accompanied with higher levels of mRNA for Cav1.2 $\alpha$ (2.93 \pm 0.57 fold increase, $n=10, P<0.05)$ and for NCX1 $(3.24 \pm 1.22$ fold increase, $n=9, P<0.05$ ) relative to glyceraldehyde 3phosphate dehydrogenase (GAPDH), as a housekeeping gene.

Male human iPS-CMs treated with 17- $\beta$-estradiol showed a trend for increased peak current density at $10 \mathrm{mV}$ as compared to vehicle-treated iPS-CMs $(17-\beta$ estradiol-treated $-4.49 \pm 0.50 \mathrm{pA} / \mathrm{pF}, n=5$ vs. vehicletreated $-3.19 \pm 0.88, n=5$, NS at $P<0.05$ ) (Fig. 5a). There was no effect of $17-\beta$-estradiol on $\mathrm{I}_{\mathrm{NCX}}$ in male myocytes as compared to vehicle (Fig. $5 \mathrm{~b}$ ).

\section{Discussion}

Our earlier findings in female rabbits linked the initiation of EADs and TdP to regions at the base of the ventricles where there was higher expression of Cav1.2 $\alpha 1$ and NCX1, their mRNA and their respective currents $\mathrm{I}_{\mathrm{Ca}, \mathrm{L}}$ and $\mathrm{I}_{\mathrm{NCX}}$. Here, we analyzed the density of ion channel proteins in left ventricles from healthy human donor hearts and found that adult women, similar to female rabbits, have significantly higher levels of Cav1.2 $\alpha 1$ and NCX1 at the base of the epicardium compared to the apex. This difference was sex-and age-dependent as it did

Table 3 Distribution of key ion channel proteins in human myocardium and calculations regarding base-apex differences

\begin{tabular}{|c|c|c|c|c|c|}
\hline Protein & Group & Base & Apex & \% Difference & $P$ value \\
\hline \multirow[t]{3}{*}{ Cav1.2a } & Men & $0.49 \pm 0.1$ & $0.47 \pm 0.1$ & $4.1 \%$ & 1.0000 \\
\hline & Adult women & $0.57 \pm 0.12$ & $0.38 \pm 0.09$ & $48.8 \% *$ & 0.0002 \\
\hline & Postm. women & $0.74 \pm 0.25$ & $0.59 \pm 0.17$ & $24.1 \%$ & 0.5625 \\
\hline \multirow[t]{3}{*}{$N C X 1$} & Men & $0.71 \pm 0.07$ & $0.64 \pm 0.13$ & $10.9 \%$ & 0.6875 \\
\hline & Adult women & $0.68 \pm 0.18$ & $0.41 \pm 0.12$ & $67.4 \% *$ & 0.0024 \\
\hline & Postm. women & $0.67 \pm 0.1$ & $0.63 \pm 0.15$ & $6 \%$ & 0.8438 \\
\hline \multirow[t]{3}{*}{ SERCA2a } & Men & $2.67 \pm 1.19$ & $1.76 \pm 0.37$ & $52.2 \%$ & 1.0000 \\
\hline & Adult women & $2.43 \pm 0.59$ & $1.44 \pm 0.33$ & $68.7 \% *$ & 0.0398 \\
\hline & Postm. women & $0.94 \pm 0.23$ & $0.99 \pm 0.28$ & $-5.8 \%$ & 0.5625 \\
\hline \multirow[t]{3}{*}{ RyR2 } & Men & $0.95 \pm 0.28$ & $0.94 \pm 0.14$ & $0.5 \%$ & 1.0000 \\
\hline & Adult women & $0.41 \pm 0.11$ & $0.5 \pm 0.11$ & $-17.3 \%$ & 0.3804 \\
\hline & Postm. women & $0.26 \pm 0.09$ & $0.22 \pm 0.04$ & $17.6 \%$ & 0.6875 \\
\hline \multirow[t]{3}{*}{ Nav1.5 } & Men & $1.96 \pm 0.35$ & $1.97 \pm 0.33$ & $-0.8 \%$ & 1.0000 \\
\hline & Adult women & $1.16 \pm 0.2$ & $1.18 \pm 0.28$ & $-1.8 \%$ & 0.8394 \\
\hline & Postm. women & $1.03 \pm 0.13$ & $1.21 \pm 0.19$ & $-15 \%$ & 0.2188 \\
\hline \multirow[t]{3}{*}{ hERG } & Men & $0.19 \pm 0.09$ & $0.09 \pm 0.03$ & $97 \%$ & 0.6250 \\
\hline & Adult women & $0.17 \pm 0.08$ & $0.46 \pm 0.24$ & $-63.4 \%$ & 0.1230 \\
\hline & Postm. women & $0.35 \pm 0.15$ & $0.24 \pm 0.09$ & $47.8 \%$ & 0.1250 \\
\hline
\end{tabular}




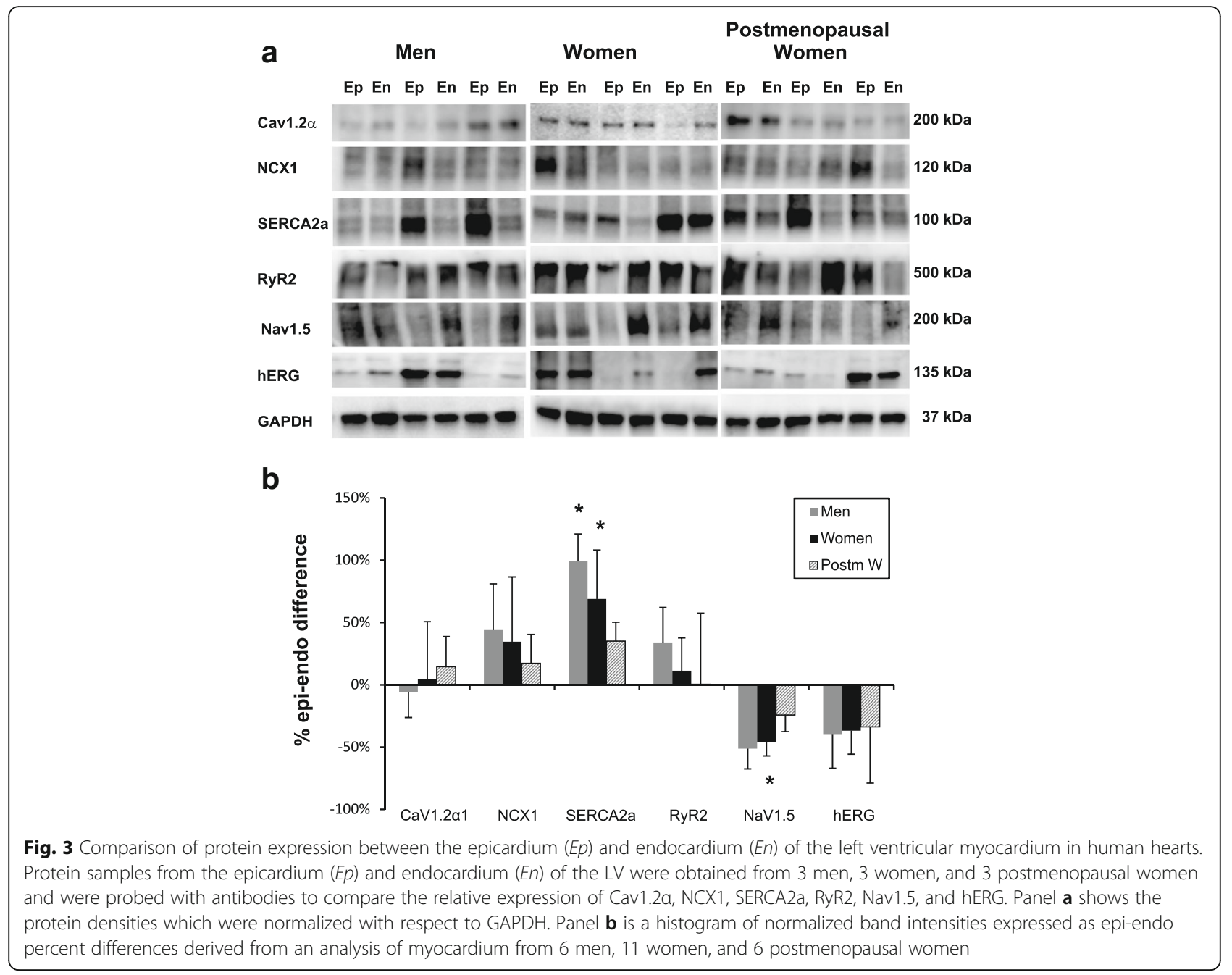

not occur in adult men or in postmenopausal women supporting the interpretation that estrogen regulates the expression of these proteins. Moreover, female human cardiomyocytes derived from induced pluripotent stem cells responded to estrogen $(1 \mathrm{nM})$ in the culture medium by a genomic upregulation (in 1-2 days) of mRNA levels and current densities of $\mathrm{I}_{\mathrm{Ca}, \mathrm{L}}$ and $\mathrm{I}_{\mathrm{NCX}}$.

In female rabbit hearts, we recently showed that the higher expression of Cav1.2 $\alpha$ and NCX1 produce aberrant systolic $\mathrm{Ca}^{2+}$ handling that trigger EADs and arrhythmias under conditions of repolarization delay, namely bradycardia [29] and drug-induced long QT [35]. Although the link between repolarization delay, $\mathrm{Ca}^{2+}$ overload, and arrhythmias was demonstrated in rabbit hearts, the same mechanism most likely applies to human hearts because sex differences in arrhythmia risk in rabbits closely match the profile of human arrhythmias associated with repolarization delays [20]. The base-apex heterogeneities of cellular $\mathrm{Ca}^{2+}$ handling are a result of an upregulation of $\mathrm{I}_{\mathrm{C}, \mathrm{L}}$ and $\mathrm{I}_{\mathrm{NCX}}$ by 17 - $\beta$-estradiol at myocytes isolated from the base of the ventricles $[14,21,32]$. The higher density of $\mathrm{I}_{\mathrm{Ca}, \mathrm{L}}$ and $\mathrm{I}_{\mathrm{NCX}}$ is mediated by estrogen receptors ( $\alpha$ and $\beta$ isoforms: ER $\alpha$ and ER $\beta$ ), requires $24-48 \mathrm{~h}$, and was inhibited by blockers of transcription or translation; hence, estrogen acts via a genomic mechanism [14, 32]. Agonists of both ER $\alpha$ and ER $\beta$ upregulate NCX1, whereas only agonists of ER $\alpha$ upregulate Cav1.2 $\alpha$. Moreover, in silico analysis of the promoter region of human and rabbit CACNA1C detected 8 high-probability estrogen receptor ER $\alpha$ (but not ER $\beta$ ) binding sites within the first 500 nucleotides of the promoter region (at http://genome.ucsc.edu and BIOBASE Knowledge Library). Chip-on-chip analysis of the human CACNA1C detected the same 8 high-quality ER $\alpha$ binding sites in the promoter region in human MCF-7 cells [36]. The analysis suggests that estrogen regulates the transcription of the gene that encodes for Cav1.2 $\alpha$ in human and rabbit hearts via ER $\alpha$ (but not ER $\beta$ ) by a "classical" genomic mechanism. Consistent with bioinformatics findings, we now show that estrogen upregulates $\mathrm{I}_{\mathrm{Ca}, \mathrm{L}}$ in isolated human iPS-derived cardiomyocytes.

An interesting unresolved question is why myocytes from the base respond to estrogen treatment but myocytes 


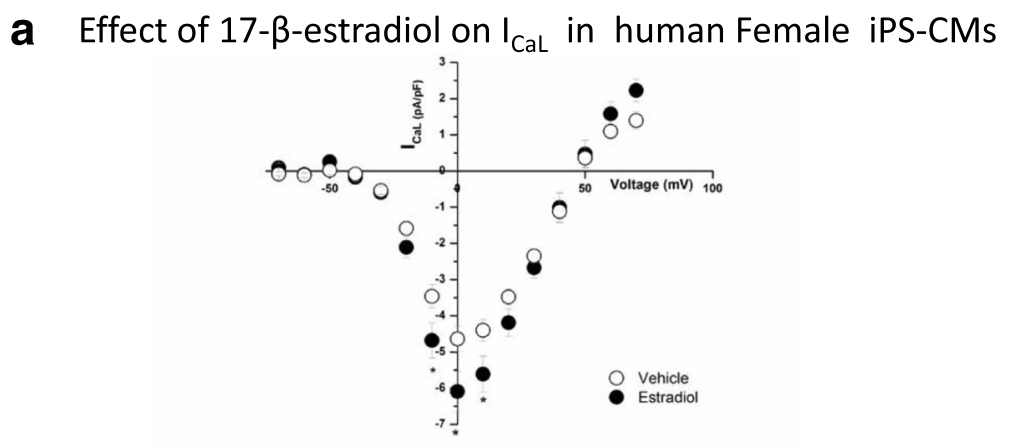

b Effect of $17-\beta$-estradiol on $I_{N C X}$ in human Female iPS-CMs

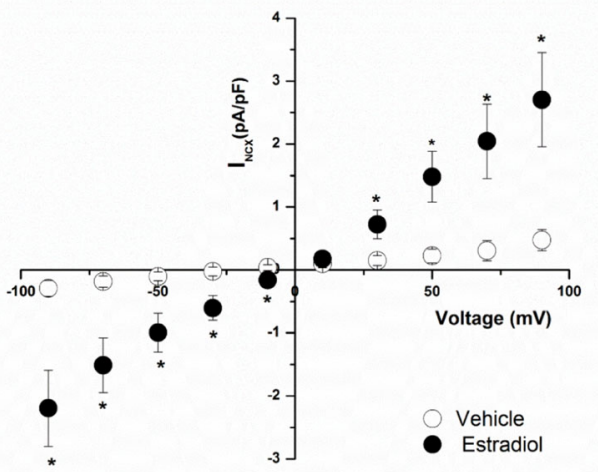

Fig. 4 Effect of E2 incubation on $I_{C a, L}$ and $I_{N C X}$ of female human iPS-CMs. a $I_{C a, L}$ current-voltage relationship from cardiac myocytes derived from hiPS cells was measured in cells cultured with $1 \mathrm{nM}$ E2 (filled circles, $n=13$ ) and compared to those cultured with vehicle (empty circles, $n=15$ ). $I_{C a, L}$ was significantly increased by E2 incubation. ( $\left.{ }^{*} P<0.05\right)$. $\left.\mathbf{b}\right|_{\text {NCX }}$ was measured as a function of voltage in female human iPS-CMs that were incubated with estradiol (filled circles, $n=5$ ) and compared to iPS-CMs incubated with the vehicle (control) (empty circles, $n=5$ ). There was a significant increase in $I_{\text {NCX }}$ when incubated with $E 2 .{ }^{*} P<0.05$

from the apex do not. A possible mechanism could be differences in the expression of receptor ER $\alpha$ and ER $\beta$ between the apex and base. However, we showed by Western blot analysis that both receptors are equally expressed at the base and apex of ventricles in both male and female myocardium [32]. A promising alternative mechanism to explain base-apex differences in the response to estrogen is to analyze base-apex differences in the activation of transcription factors from the same hearts, an approach that is only applicable to animal models.

Besides base-apex differences on the epicardium, we also examined epicardium-to-endocardium differences. In rabbit hearts, endocardial cells from the base did not respond to estrogen [14] and both Cav1.2 $\alpha$ and NCX1 showed a tendency to be higher on the epicardium than the endocardium confirming an earlier study of higher expression of Cav1.2 $\alpha$ on the female rabbit epicardium [37]. Transmural dispersion of repolarization measured with plunge electrodes was greater in female than male rabbits and contributed to the higher incidence of torsade de pointes in female hearts [38].

In dog hearts, $\mathrm{I}_{\mathrm{NCX}}$ and $\mathrm{I}_{\mathrm{C}, \mathrm{L}}$ densities were greater on the epicardium than endocardium [39] and the sarcoplasmic reticulum (SR) $\mathrm{Ca}^{2+}$ load was higher in the epicardium. The higher $\mathrm{I}_{\mathrm{NCX}}$ and SR load is consistent with the higher SERCA2a levels on the epicardium of human hearts, which was found in non-failing and failing hearts [40] and in normal male and female hearts (Fig. 3). Nav1.5 was found to be higher on the endocardium by Gaborit et al. [41], and we show a similar tendency irrespective of sex.

The higher expression of Cav1.2 $\alpha$ at the base vs apex is observed in women and in rabbits and so are increases in NCX1. One might speculate that the higher influx of $\mathrm{Ca}^{2+}$ occurring through $\mathrm{I}_{\mathrm{Ca}, \mathrm{L}}$ is somewhat balanced by the higher $\mathrm{Ca}^{2+}$ efflux through $\mathrm{I}_{\mathrm{NCX}}$. While there are sex differences in $\mathrm{Ca}^{2+}$ handling across the plasma membrane, little is known regarding sex differences in $\mathrm{Ca}^{2+}$ transport across the sarcoplasmic reticulum. In women, SERCA2a was more abundant at the base compared to the apex, and this large spatial gradient was not observed in men or postmenopausal women; in contrast, there were no spatial gradients of RyR2 in all three groups. The gradient of SERCA2a seen in women was not observed in female but was striking in male rabbit hearts (Fig. 2). Further studies will be needed to 


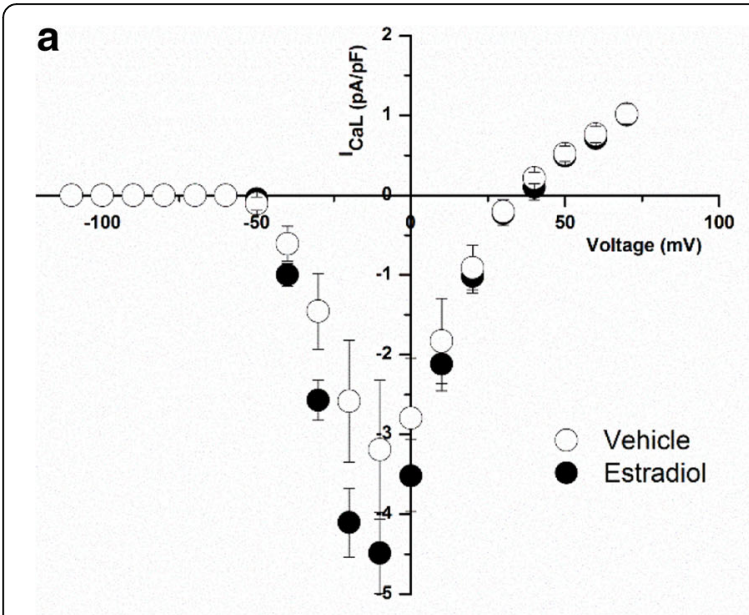

b

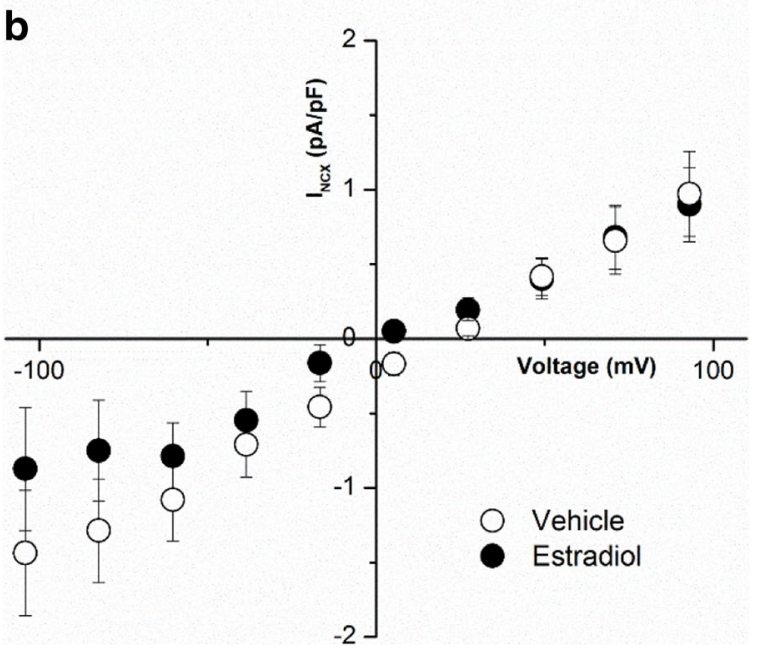

Fig. 5 Effect of E2 incubation on $I_{C a, L}$ and $I_{N C X}$ of male human iPS-CMs. a Effect of $17-\beta$-estradiol on $I_{C a, L}$ in male iPS-CMs. $I_{C a, L}$ was measured as described in the methods in male iPS-CMs following treatment with 17- $\beta$-estradiol (filled circles) and vehicle (empty circles). 17- $\beta$-estradiol treatment displayed a small but not significant increase in $\mathrm{I}_{\mathrm{Ca}, \mathrm{L}}$ as compared to vehicle treatment. $\mathbf{b}$ Effect of $17-\beta$-estradiol on $I_{\text {NCX }}$ in male iPS-CMs. Shown are the averaged current density for $I_{N C X}$ obtained from male iPS-CMs treated with 17- $\beta$-estradiol (filled circles) and vehicle (empty circles)

determine the functional consequences of these regional sex differences in SERCA2a in terms of the amplitude and rate of SR $\mathrm{Ca}^{2+}$ uptake and whether these differences are modulated by sex hormones.

Limitations of availability and viability in culture of healthy human ventricular myocytes precluded studying the estrogen response of isolated myocytes from the base and apex of normal human hearts under voltage clamp. Instead, we tested human iPS-CMs which are known to retain many features of adult ventricular myocytes [34]. As shown here, estrogen-treated female human iPS-CMs exhibited a genomic upregulation of Cav1.2 $\alpha 1$ and NCX1 akin to cells from the base of the heart, even though heterogeneity of iPS-CMs may obscure larger changes associated with regional differences of the heart. At physiological membrane potentials $(+10$ to $90 \mathrm{mV}), \mathrm{I}_{\mathrm{NCX}}$ was considerably greater in male than in female human iPS-CMs (for instance, $\mathrm{I}_{\mathrm{NCX}}=0.19 \mathrm{pA} / \mathrm{pF}$ in females and $-1.2 \mathrm{mV}$ in males; at $-80 \mathrm{mV}$ ). Incubation with estrogen tended to reduce $\mathrm{I}_{\mathrm{NCX}}$ in male and significantly increased $\mathrm{I}_{\mathrm{NCX}}$ in female iPS-CMs. The endogenously greater $\mathrm{I}_{\mathrm{NCX}}$ in males could be due to a number of factors involving iPS-CM maturation and intracellular ionic concentrations.

Unfortunately, sex hormone levels of the organ donors are unknown, and we can only surmise that the donors had normal physiological levels. Nevertheless, the myocardium of young adult females exhibited regional differences in the expression of Cav1.2 $\alpha 1$ and NCX1, a profile that was absent in men and in postmenopausal women.

The lack of regional differences in ion channel and calcium-handling protein expression in postmenopausal hearts (reduced estrogen levels) also serves as corroborating evidence that the heterogeneities observed in young adult women are due to genomic regulation by estrogen, similar to findings in female rabbits.

There is an extensive literature focused on the effects of sex steroids on $\mathrm{K}^{+}$channels and QT intervals and related to sex differences in arrhythmia risk. But most studies have rarely paid attention to regional (base-apex) differences in ion channel distribution, calcium-handling mechanisms, or genomic regulation [41]. Studies on repolarizing $\mathrm{K}^{+}$currents explain differences in action potential duration but not the initiation of EADs which trigger TdP. Indeed, the formation of EADs has been shown to result from cellular elevation of $\mathrm{Ca}^{2+}$ that activates $\mathrm{I}_{\mathrm{NCX}}$ (forward mode) and elicits the reactivation of $\mathrm{I}_{\mathrm{Ca}, \mathrm{L}}$. Our study is the first to demonstrate that base-apex differences on the epicardium of the human heart are sex-dependent and occur only in adult women and that these differences trump transmural heterogeneities, which, if they occur, do not seem to be sexrelated. Therefore, the higher incidence of drug-induced TdP in women and in female animals could rather be explained by a base-apex heterogeneity of ion channel and calcium-handling protein expression on the epicardium.

\section{Conclusions}

It has long been assumed that sex differences in arrhythmia risk in cases of repolarization delay (e.g., bradycardia and long QT) was due to a "reduced repolarization reserve," (e.g., a suppression of repolarizing $\mathrm{K}^{+}$currents) in female hearts. However, optical mapping revealed that in rabbit hearts, these arrhythmias were initiated by abnormalities in $\mathrm{Ca}^{2+}$ handling. Further studies showed that estrogen imparted these sex differences in adult females through a genomic upregulation of the L-type $\mathrm{Ca}^{2+}$ channel and the $\mathrm{Na}^{+}-\mathrm{Ca}^{2+}$ exchanger. These findings altered the mechanisms of action of class III anti-arrhythmic agents and 
shifted to $\mathrm{Ca}^{2+}$ overload as a target to suppress torsade de pointes. The central goal of this study is to examine the human relevance of findings obtained in rabbit hearts. In principle, equivalent experiments would require tissue and cell isolation from different regions of healthy human hearts to measure the genomic effects of estrogen. Instead, we used postmortem myocardium from healthy hearts to analyze sex differences in ion channel expression and human cardiomyocytes derived from induced pluripotent stem cells to measure the functional effects of estrogen on $\mathrm{Ca}^{2+}$ currents. The data shows that there is a close correspondence between rabbit and human myocyte responses to estrogen at very low estrogen concentrations. These genomic effects of estrogen at $1 \mathrm{nM}$ trump the acute effects of estrogen on ionic currents observed at micromolar concentrations. Hence, the higher risk of women to torsade de pointes may be caused by a greater $\mathrm{Ca}^{2+}$ overload in conditions of repolarization delays. Estrogen binding to estrogen receptor $\alpha$ may act as a transcription factor to upregulate channel expression and promote $\mathrm{Ca}^{2+}$ overload. From a public health point of view, the study suggests that $\mathrm{Ca}^{2}$ ${ }^{+}$-handling proteins may be important targets to suppress torsade de pointes.

\section{Abbreviations \\ Cav1.2a: Primary subunit of the L-type $\mathrm{Ca}^{2+}$ channel protein;

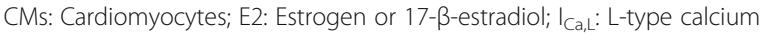 current; I INC: Sodium-calcium exchange current; iPS-CM: CM derived from induced pluripotent stem cells; LQTS2: Long QT syndrome type 2; NCX1: Sodium-calcium exchange protein; TdP: Torsade de pointes}

\section{Acknowledgements}

Thanks are due to Mr. Shanping Shi for his technical help with the voltageclamp studies, Ms. Lisa Rising for helping with the protein isolation and Western blots, Dr. Laurie Kerchner for her expertise with proteomics and antibodies, and Ms. Beth Gabris for her technical assistance with iPS-CMs and protein isolation.

\section{Funding}

Postdoctoral Fellowship from the American Heart Association 1OPOST3430026 to RP, a grant from the Hungarian Scientific Research Found OTKA NK-104331 to AV, NIH RO1 grants from NHLBI, HL093631 to GB, HL062465 to RLR, and HL070722, HL093074 to GS.

\section{Availability of data and materials}

Data sharing is not applicable to this article as no datasets were generated or analyzed during the current study. Please contact the author for requests of the complete Western blot data and verification of antibodies used in the study.

\section{Authors' contributions}

RP was a postdoc in GS's lab; she isolated the proteins from human myocardium tissues, tested and verified numerous antibodies, and ran and analyzed the Western blots. GB handled the voltage-clamped iPS-CMs. AL is a postdoc in GB's lab who conducted the voltage clamp and ran the RT-PCR on IPS-CMs. RR developed the electronic insertion of the $\mathrm{I}_{\mathrm{K} 1}$ current to make possible to measure the action potentials of iPS-CMs before measuring the currents. IB and AV procured the human ventricular muscles rapidly to avoid degradation taking great care to dissect the muscle from the same locations of the base and apex of the heart. GS initiated the study on human heart muscle and IPS-CMs because of extensive experiments on sex differences in the rabbit and arrhythmia phenotype based on optical mapping. GS wrote the final manuscript. All the authors revised the manuscript and contributed to its current state. All authors read and approved the final manuscript.

\section{Ethics approval and consent to participate}

The investigations conformed to the principles of the Declaration of Helsinki. The experimental protocols were approved by the University of Szeged and National Scientific and Research Ethical Review Boards (No. 51-57/1997 OEj) and by the Scientific and Research Ethical Committee of the Medical Scientific Board at the Hungarian Ministry of Health (ETT-TUKEB) under ethical approval No. 4991-0/2010-1018EKU (339/PI/010). The authors approve the ethics declaration and consent to participate as co-authors.

\section{Consent for publication}

Not applicable.

\section{Competing interests}

The authors declare that they have no competing interests.

\section{Publisher's Note}

Springer Nature remains neutral with regard to jurisdictional claims in published maps and institutional affiliations.

\section{Author details}

'Department of Bioengineering and the Department of Medicine, Heart and Vascular Institute, University of Pittsburgh, Pittsburgh, PA 15261, USA. ${ }^{2}$ Center for Cellular and Systems Electrophysiology, University at Buffalo, State University of New York, Buffalo, NY 14214, USA. ${ }^{3}$ Department of Physiology and Biophysics, University at Buffalo, State University of New York, Buffalo, NY 14214, USA. ${ }^{4}$ Obstetrics-Gynecology, University at Buffalo, State University of New York, Buffalo, NY 14214, USA. ${ }^{5}$ Department of Pharmacology and Pharmacotherapy, University of Szeged, Szeged, Hungary. ${ }^{6}$ MTA-SZTE Research Group for Cardiovascular Pharmacology, Hungarian Academy of Sciences, Szeged, Hungary. ${ }^{7}$ Current Address: Ludwig Boltzmann Institute for Lung Vascular Research, Graz, Austria. ${ }^{8}$ Department of Bioengineering and the Department of Medicine, Heart and Vascular Institute, University of Pittsburgh, 3550 Terrace Street, 5628 Scaife Hall, Pittsburgh, PA 15261, USA.

Received: 28 April 2017 Accepted: 4 August 2017

Published online: 14 August 2017

\section{References}

1. Morita H, Wu J, Zipes DP. The QT syndromes: long and short. Lancet. 2008; 372:750-63.

2. Pollard CE, Abi Gerges N, Bridgland-Taylor MH, Easter A, Hammond TG, Valentin JP. An introduction to QT interval prolongation and non-clinical approaches to assessing and reducing risk. Br J Pharmacol. 2010;159:12-21.

3. Kallergis EM, Goudis CA, Simantirakis EN, Kochiadakis GE, Vardas PE. Mechanisms, risk factors, and management of acquired long QT syndrome: a comprehensive review. Sci World J. 2012;2012:212178-86.

4. Perrin MJ, Subbiah RN, Vandenberg JI, Hill AP. Human ether-a-go-go related gene (hERG) K+ channels: function and dysfunction. Prog Biophys Mol Biol. 2008;98:137-48.

5. Drici MD, Clement N. Is gender a risk factor for adverse drug reactions? The example of drug-induced long QT syndrome. Drug Saf. 2001;24:575-85.

6. Levine E, Rosero SZ, Budzikowski AS, Moss AJ, Zareba W, Daubert JP. Congenital long QT syndrome: considerations for primary care physicians. Cleve Clin J Med. 2008;75:591-600.

7. Vincent GM. Long QT syndrome. Cardiol Clin. 2000;18:309-25.

8. Splawski I, Shen J, Timothy KW, Lehmann MH, Priori S, Robinson JL, Moss AJ, Schwartz PJ, Towbin JA, Vincent GM, Keating MT. Spectrum of mutations in long-QT syndrome genes. KVLQT1, HERG, SCN5A, KCNE1, and KCNE2. Circulation. 2000;102:1178-85.

9. Coker SJ. Drugs for men and women —how important is gender as a risk factor for TdP? Pharmacol Ther. 2008;119:186-94.

10. Roden DM, Abraham RL. Refining repolarization reserve. Heart Rhythm. 2011;8: 1756-7.

11. Lehmann MH, Hardy S, Archibald D, MacNeil DJ. JTc prolongation with d,Isotalol in women versus men. Am J Cardiol. 1999;83:354-9.

12. Marban E, Robinson SW, Wier WG. Mechanisms of arrhythmogenic delayed and early afterdepolarizations in ferret ventricular muscle. J Clin Invest. 1986; 78:1185-92.

13. Volders PG, Vos MA, Szabo B, Sipido KR, de Groot SH, Gorgels AP, Wellens HJ, Lazzara R. Progress in the understanding of cardiac early afterdepolarizations 
and torsades de pointes: time to revise current concepts. Cardiovasc Res. 2000; 46:376-92.

14. Chen G, Yang X, Alber S, Shusterman V, Salama G. Regional genomic regulation of cardiac sodium-calcium exchanger by oestrogen. J Physiol. 2011;589:1061-80.

15. Drici MD, Knollmann BC, Wang WX, Woosley RL. Cardiac actions of erythromycin: influence of female sex. JAMA. 1998;280:1774-6.

16. Rautaharju PM, Zhou SH, Wong S, Calhoun HP, Berenson GS, Prineas R, Davignon A. Sex differences in the evolution of the electrocardiographic QT interval with age. Can J Cardiol. 1992;8:690-5.

17. Buber J, Mathew J, Moss AJ, Hall WJ, Barsheshet A, McNitt S, Robinson JL, Zareba W, Ackerman MJ, Kaufman ES, Luria D, Eldar M, et al. Risk of recurrent cardiac events after onset of menopause in women with congenital long-QT syndrome types 1 and 2. Circulation. 2011;123:2784-91.

18. Roden DM. Repolarization reserve - a moving target. Circulation. 2008;118:981-2.

19. Shah M, Carter C. Long QT syndrome: a therapeutic challenge. Ann Pediatr Cardiol. 2008;1:18-26.

20. Salama G, Bett GC. Sex Differences in the mechanisms underlying long QT syndrome. Am J Physiol Heart Circ Physiol. 2014;307(5):H640-H648.

21. Sims C, Reisenweber S, Viswanathan PC, Choi BR, Walker WH, Salama G. Sex, age, and regional differences in L-type calcium current are important determinants of arrhythmia phenotype in rabbit hearts with drug-induced long QT type 2. Circ Res. 2008;102:e86-100.

22. Liu T, Choi BR, Drici MD, Salama G. Sex modulates the arrhythmogenic substrate in prepubertal rabbit hearts with Long QT 2. J CardiovasC Electrophysiol. 2005;16:516-24.

23. Goldenberg I, Moss AJ, Peterson DR, McNitt S, Zareba W, Andrews ML Robinson JL, Locati EH, Ackerman MJ, Benhorin J, Kaufman ES, Napolitano C, et al. Risk factors for aborted cardiac arrest and sudden cardiac death in children with the congenital long-QT syndrome. Circulation. 2008;117:2184-91.

24. Drici MD, Burklow TR, Haridasse V, Glazer RI, Woosley RL. Sex hormones prolong the QT interval and downregulate potassium channel expression in the rabbit heart. Circulation. 1996;94:1471-4

25. Hara M, Danilo P Jr, Rosen MR. Effects of gonadal steroids on ventricular repolarization and on the response to E4031. J Pharmacol Exp Ther. 1998;285: 1068-72.

26. Pham TV, Sosunov EA, Gainullin RZ, Danilo P Jr, Rosen MR. Impact of sex and gonadal steroids on prolongation of ventricular repolarization and arrhythmias induced by I(K)-blocking drugs. Circulation. 2001;103:2207-12.

27. Nemec J, Kim JJ, Gabris B, Salama G. Calcium oscillations and T-wave lability precede ventricular arrhythmias in acquired long QT type 2. Heart Rhythm. 2010;7:1686-94

28. Choi BR, Burton F, Salama G. Cytosolic Ca2+ triggers early afterdepolarizations and Torsade de Pointes in rabbit hearts with type 2 long QT syndrome. J Physiol. 2002;543:615-31.

29. Kim JJ, Nemec J, Papp R, Strongin R, Abramson JJ, Salama G. Bradycardia alters Ca2+ dynamics enhancing dispersion of repolarization and arrhythmia risk. Am J Phys Heart Circ Phys. 2013;304:H848-60.

30. Merz CN, Moriel M, Rozanski A, Klein J, Berman DS. Gender-related differences in exercise ventricular function among healthy subjects and patients. Am Heart J. 1996;131:704-9.

31. Verkerk AO, Wilders R, Veldkamp MW, de Geringel W, Kirkels JH, Tan HL. Gender disparities in cardiac cellular electrophysiology and arrhythmia susceptibility in human failing ventricular myocytes. Int Heart J. 2005;46:1105-18.

32. Yang X, Chen G, Papp R, Defranco DB, Zeng F, Salama G. Oestrogen upregulates $\mathrm{L}$-type $\mathrm{Ca}^{2+}$ channels via oestrogen-receptor- by a regional genomic mechanism in female rabbit hearts. J Physiol. 2012;590:493-508.

33. Pham TV, Robinson RB, Danilo P Jr, Rosen MR. Effects of gonadal steroids on gender-related differences in transmural dispersion of L-type calcium current. Cardiovasc Res. 2002;53:752-62

34. Kim JJ, Yang L, Lin B, Zhu X, Sun B, Kaplan AD, Bett GC, Rasmusson RL, London B, Salama G. Mechanism of automaticity in cardiomyocytes derived from human induced pluripotent stem cells. J Mol Cell Cardiol. 2015;81 C:81-93.

35. Kim J, Nemec J, Li Q, Salama G. Synchronous systolic subcellular Ca2 +- elevations underlie ventricular arrhythmia in drug-induced long QT type 2. Circulation: Arrhythmia and Electrophysiology. 2015; in press

36. Welboren WJ, van Driel MA, Janssen-Megens EM, van Heeringen SJ, Sweep FC, Span PN, Stunnenberg HG. ChIP-Seq of ERalpha and RNA polymerase II defines genes differentially responding to ligands. EMBO J. 2009;28:1418-28.

37. Pham TV, Rosen MR. Sex, hormones, and repolarization. Cardiovasc Res. 2002:53: 740-51.
38. Ruan YF, Liu N, Zhou Q, Li Y, Wang L. Experimental study on the mechanism of sex difference in the risk of torsade de pointes. Chin Med J. 2004;117:538-41.

39. Xiong W, Tian Y, DiSilvestre D, Tomaselli GF. Transmural heterogeneity of $\mathrm{Na}$ +-Ca2+ exchange: evidence for differential expression in normal and failing hearts. Circ Res. 2005;97:207-9.

40. Lou Q, Fedorov W, Glukhov AV, Moazami N, Fast VG, Efimov IR. Transmural heterogeneity and remodeling of ventricular excitation-contraction coupling in human heart failure. Circulation. 123:1881-90.

41. Gaborit N, Varro A, Le Bouter S, Szuts V, Escande D, Nattel S, Demolombe S. Gender-related differences in ion-channel and transporter subunit expression in non-diseased human hearts. J Mol Cell Cardiol. 49:639-46.

\section{Submit your next manuscript to BioMed Central and we will help you at every step:}

- We accept pre-submission inquiries

- Our selector tool helps you to find the most relevant journal

- We provide round the clock customer support

- Convenient online submission

- Thorough peer review

- Inclusion in PubMed and all major indexing services

- Maximum visibility for your research

Submit your manuscript at www.biomedcentral.com/submit
) Biomed Central 